Ebisu Ebisu

Études japonaises Études japonaises

48 | automne-hiver 2012

Naissance d'une revue féministe au Japon : Seitō

(1911-1916)

\title{
Jean-Jacques TSCHUDIN, Histoire du théâtre classique
} japonais

Toulouse, Anacharsis, coll. « essais », 2011, 506 p.

Sylvie Beaud

\section{OpenEdition}

Journals

Édition électronique

URL : http://journals.openedition.org/ebisu/684

DOI : 10.4000/ebisu.684

ISSN : 2189-1893

Éditeur

Institut français de recherche sur le Japon à la Maison franco-japonaise (UMIFRE 19 MEAE-CNRS)

Édition imprimée

Date de publication : 1 septembre 2012

Pagination : 203-205

ISSN : $1340-3656$

Référence électronique

Sylvie Beaud, « Jean-Jacques tschudin, Histoire du théâtre classique japonais », Ebisu [En ligne], 48| automne-hiver 2012, mis en ligne le 20 mars 2014, consulté le 22 septembre 2020. URL : http:// journals.openedition.org/ebisu/684; DOI : https://doi.org/10.4000/ebisu.684

Ce document a été généré automatiquement le 22 septembre 2020.

(c) Institut français de recherche sur le Japon à la Maison franco-japonaise 


\title{
Jean-Jacques TSCHUDIN, Histoire du théâtre classique japonais
}

Toulouse, Anacharsis, coll. « essais », 2011, 506 p.

\author{
Sylvie Beaud
}

\section{RÉFÉRENCE}

Jean-Jacques TSCHUDIN, Histoire du théâtre classique japonais, Toulouse, Anacharsis, coll. « essais », 2011, 506 p.

1 L'auteur de l'Histoire du théâtre classique japonais signe un ouvrage encyclopédique d'une très riche érudition, qui n'en reste pas moins d'une lecture aisée et agréable. L'ouvrage rend compte des dynamiques politiques et stylistiques à l'œuvre à travers l'histoire des différents genres théâtraux des origines à nos jours, soit sur près de quinze siècles. En filigrane de ces parcours, ce sont ainsi les mutations de la société japonaise au cours du temps qui sont données à voir. Aussi, malgré la fréquence de termes vernaculaires dans le texte, ce livre intéressera-t-il un public large : curieux du théâtre japonais, étudiants, chercheurs ou spécialistes d'autres théâtres.

2 L'ouvrage se compose de sept parties complétées par 55 pages d'annexes: bibliographie, glossaire des termes techniques, répertoire des ouvrages japonais cités et index des personnages historiques. Il est illustré de nombreuses photographies et de quelques planches. Il associe un découpage chronologique - que délimitent les parties à un classement thématique à l'intérieur des chapitres.

La première partie fait démarrer l'histoire du théâtre aux mythes fondateurs qui nous sont parvenus notamment dans les chroniques historiques compilées au début du vIII ${ }^{\mathrm{e}}$ siècle. Les chants et danses antiques à partir desquels des formes plus théatralisées se sont développées trouvent leur origine dans les rituels de cour constitués grâce aux apports des fêtes villageoises. 
4 Mais les sources étant trop ténues pour permettre de mesurer leur influence sur le développement du théâtre avant l'arrivée des pratiques continentales, c'est à ces dernières que la deuxième partie est consacrée. Poèmes chantés, spectacles et danses masqués, arts forains venus de Corée et de Chine sont examinés. Indépendamment de la période historique concernée, cette partie intéressera particulièrement les spécialistes des théâtres du monde sinisé, qui y trouveront des pistes de comparaisons historiques et des éléments de réflexion sur les pratiques contemporaines.

5 La troisième partie, qui expose la naissance et la transformation des différents genres et styles d'arts dramatiques (au sens large, incluant les danses, les récits chantés jusqu'à l'art des conteurs), permet de situer l'arrivée de certains instruments de musique (luth biwa 琵琶, shamisen 三味線) à la fin de la période Heian. L'importance du rôle de la cour dans le patronage des artistes, avec la création de centres de formation, est également mise en évidence.

6 La quatrième partie décrit comment certaines formes se rejoignant et se formalisant progressivement vont donner naissance au nō 能 tel que nous le connaissons aujourd'hui. L'auteur retrace le parcours biographique des fondateurs et des premiers théoriciens du nō, pour ensuite mettre l'accent sur la dramaturgie et les éléments de scénographie. Enfin, le dernier chapitre de cette quatrième partie est consacré au kyōgen 狂言, intermède comique inscrit dans un spectacle de nō.

7 Sur le plan chronologique, les cinquième et sixième parties renvoient aux arts florissants à l'époque d'Edo : le théâtre de poupées (bunraku 文楽) et le kabuki 歌舞伎. J.-J. Tschudin aborde les caractéristiques du théâtre de poupées avant de détailler l'histoire de la formation de cet art, de ses dramaturges et de leurs styles. Il livre un résumé conséquent d'une vingtaine de pièces majeures qui étaient pour la plupart inaccessibles en français jusqu'alors. La sixième partie, de loin la plus longue, traite du kabuki. Après un bref rappel de la formation du genre, l'auteur relate les types de scénarios qui figurent au répertoire ainsi que les types de rôles. Les formes de jeu, les codes et la machinerie sont détaillés.

8 Enfin, le dernier chapitre décrit la vie au théâtre, permettant au lecteur d'imaginer l'ambiance des spectacles à l'époque d'Edo et ce qu'il en est encore aujourd'hui. Parvenu quasiment au terme de son déroulement historique, l'ouvrage contient une dernière partie qui traite des arts théâtraux classiques aux époques moderne et contemporaine, puis conclut sur la pérennité de ces formes grâce à leur haut degré de stylisation.

9 L'ouvrage fait ainsi œuvre d'exhaustivité, tout en mettant l'accent sur le kabuki, genre dont l'auteur est spécialiste. Pour autant, une attention est accordée à de nombreuses formes méconnues des non-spécialistes, notamment celles qui ont conduit à la formation des «trois piliers » (p. 27, p. 247) du théâtre classique japonais : nō, bunraku et kabuki. L'Histoire du théâtre classique japonais s'impose comme un compagnon de recherche qui se consulte, aussi bien dans la linéarité que de façon transversale, à tout moment. 


\section{AUTEURS}

\section{SYLVIE BEAUD}

(université de Paris Ouest Nanterre - La Défense, associée au Laboratoire d'ethnologie et de sociologie comparative [CNRS]) 